\section{Carbon fixation pathways}

\section{from Sandy Grimwade}

A symposium on the $C_{3}$ and $C_{4}$ photosynthetic pathways was held by the Ecological Society of America at the Annual Meeting of the American Institute of Biological Science in East Lansing, Michigan in August 1977.

THE fixation of atmospheric carbon dioxide into metabolic intermediates by green plants can take place by three different pathways. In the majority of plants $\mathrm{CO}$ is fixed by the classic Calvin cycle directly into ribulose diphosphate to form two molecules of phosphoglycerate- a three-carbon compound. In some plants, however, the initial carboxylation step results in the formation of $C_{t}$ compounds such as oxaloacetate, which are then decarboxylated in specialised bundle sheath cells where the released $\mathrm{CO}_{2}$ is refixed by the usual Calvin cycle. The third, and most restricted type is found mostly in succulents of arid regions. Fixation of $\mathrm{CO}_{2}$ in this case occurs into crassulacean acid.

The differences between the so-called $\mathrm{C}_{3}$ and $\mathrm{C}_{4}$ plants give rise to a wide variety of biochemical, ecological and climatological implications, some of which were discussed at the symposium.

B. N. Smith (Brigham Young University) outlined the biology of $\mathrm{C}_{3}$ and $\mathrm{C}_{4}$ plants and the resulting isotope fractionation effects. Atmospheric $\mathrm{CO}$. contains both the ${ }^{12} \mathrm{C}$ and ${ }^{13} \mathrm{C}$ stable isotopes of carbon. Compared with a standard limestone sample, the relative concentration of the ${ }^{13} \mathrm{C}$ isotope in atmospheric $\mathrm{CO}\left(\delta^{13} \mathrm{C}\right)$ is $-7 \% \ldots$ The photosynthetic fixation of atmospheric $\mathrm{CO}$ exhibits a substantial isotope effect, which differs markedly for $\mathrm{C}_{3}$ and $\mathrm{C}_{4}$ plants. As $\mathrm{CO}_{2}$ fixation is the only reaction which shows such a substantial effect, the resulting isotope depletions are reflected throughout the plant tissues. In $C_{3}$ and $C_{4}$ plants, the $\delta^{13} \mathrm{C}$ values are -26 and $-12 \%$ respectively. In addition, these isotope depletions are maintained in the herbivores which eat the plants and so on up the food chain. As these differences are so marked, they provide a valuable tool in several fields. For instance, the relative concentration of $C_{3}$ and $C_{1}$ plants in fossil animals can be estimated. The adulteration of honey-mostly from $\mathrm{C}_{3}$ plants-with

Sandy Grimwade is Assistant Editor of Nature in Washington. corn syrup, from a $\mathrm{C}_{4}$ plant, could be detected and quantified.

Any consideration of $\mathrm{C}_{3}$ and $\mathrm{C}_{4}$ metabolism in plants gives rise to two related questions-why do plants use more than one pathway for $\mathrm{CO}_{2}$ fixation and how did the pathways evolve. Answers to these questions must account for the fact that $\mathrm{C}_{4}$ metabolism is found spread throughout many plant genera, and yet no genus is composed exclusively of $C_{t}$ plants. For instance, about $50 \%$ of grass species are $C_{4}$ plants as is a smaller proportion of Compositae. The only way to account for such a patchy distribution is to hypothesise that $C_{4}$ metabolism with its attendant array of specialised enzymes and cellular anatomy arose as many as 20 times in the course of plant evolution. The alternative proposition, that it arose once or a few times is almost impossible to reconcile with accepted schemes.

The question of the rationale for more than one pathway is easier to tackle. J. R. Ehleringer (Stanford University) presented data showing the advantages of $\mathrm{C}_{4}$ metabolism in grasses in particular environmental circumstances. Measurements on whole plants of net carbon gain per unit weight show the following. At normal oxygen tension, $C_{3}$ and $C_{4}$ plants show similar efficiencies, but as $\mathrm{O}_{2}$ tension decreases, the efficiency of $\mathrm{C}_{t}$ metabolism increases whereas $C_{3}$ remains constant. Similarly, the yield of $C_{t}$ plants is constant with increasing temperature whereas the efficiency of $\mathrm{C}_{3}$ metabolism decreases. $C_{4}$ plants also have the advantage at high light intensities and low humidity. Using these data, a computer simulation of the rate of carbon gain in a $\mathrm{C}_{3}$ or $\mathrm{C}_{4}$ grass canopy in the Great Plains of the United States in July shows that as latitude increases, so does the efficiency of $C_{3}$ grasses. At $45^{\circ} \mathrm{N}$ the two types are about equal. A survey of the flora of the Great Plains reveals that in the south of Texas $\left(25^{\circ} \mathrm{N}\right)$ about $70 \%$ of the grass cover is $\mathrm{C}_{1}$, at $40^{\circ} \mathrm{N}$ the two types are equal, and at $60^{\circ} \mathrm{N}$ only $\mathrm{C}_{3}$ types are found. Thus the relative physiological advantage of $\mathrm{C}_{3}$ or $\mathrm{C}_{4}$ metabolism is directly reflected in the flora of the region.

Similarly, a survey by C. T. Harrison (University of Wyoming) of the grass types along a transect of grasslands in Wyoming shows a decrease in the percentage of the biomass composed of $C_{4}$ grasses with increasing elevation, and hence decreasing average temperature. This point is nicely reflected in measurements of the $\delta^{13} \mathrm{C}$ values of bison remains in a single burial pit in Wyoming. At the surface, the $\delta^{13} \mathrm{C}$ values reflect a diet for the bison which contains a substantial proportion of $C_{1}$ grasses. With increasing depth, and hence age, the proportion of $\mathrm{C}_{4}$ in the diet decreases until the $\delta^{13} \mathrm{C}$ value reflects a diet composed entirely of $C_{3}$ plants approximately 8,000 years ago. This is held to reflect the gradual warming of the climate, with the subsequent invasion of $\mathrm{C}_{4}$ grasses from the south over the past few millenia. $\square$

\section{Gravitation but no levitation}

\author{
by Malcolm MacCallum
}

The Eighth International Conference on General Relativity and Gravitation was held at the University of Waterloo, Ontario, Canada on 7-12 August, 1977. The organising committees, headed by M. McKiernan (University of Waterloo) and W. Israel (University of Alberta, Edmonton), provided a most enjoyable and enlightening meeting.

'GR8' proclaimed the T-shirts: they were right in more ways than one. Up to nine parallel afternoon sessions were required to accommodate more than 400 talks contributed from among the 700 or so participants. The morning plenary sessions were devoted to invited talks, mainly reviews.

Informal discussions between $\mathrm{V}$. Braginsky (Moscow), W. Unruh (University of British Columbia, Vancouver) and others evolved schemes to push the sensitivity of gravity wave detectors to the level where the instrument must be regarded as a quantum system. A factor of about one million improvement is required to measure the expected astrophysical sources, as described by $\mathrm{K}$. S. Thorne (Caltech). The active groups developing the various possibilities were all represented, and there seemed to be considerable optimism about the feasibility of the new detectors and the likelv technological spin-off from their development.

Experimental results by I. S. Shapiro (Massachusetts Institute of Technology) on time-delay data from the Viking missions to Mars, and by R. B. Partridge (Haverford College) on the isotropy of the cosmic microwave hackground contained no real surprises, anart from some unexplained and unsvstematic deviations in Shapiro's data which he tentatively ascribed to procedural errors at the tracking stations. R. Newman (University of California,

Malcolm MacCallum is a lecturer in the Department of Applied Mathematics. Queen Mary College, London. 